Disclosure of Interests: José Luis Martín-Varillas: None declared, D. Prieto-Peña: None declared, Lara Sánchez Bilbao: None declared, Eva Peña Sainz-Pardo: None declared, Belén Atienza-Mateo: None declared Monica Calderón-Goercke: None declared, Iñigo González-Mazón: None declared, Natalia Palmou-Fontana: None declared, Maria Teresa Viadero Ubierna: None declared, María Jesús Cabero: None declared, Miguel A González-Gay Grant/research support from: Prof. MA Gonzalez-Gay received grants/research supports from Abbvie, MSD, Jansen and Roche., Speakers bureau: Consultation fees/participation in company sponsored speaker's bureau from Pfizer, Lilly, Sobi, Celgene, Novartis, Roche and Sanofi., Ricardo Blanco Grant/research support from: Abbvie, MSD, and Roche, Consultant for: Abbvie, Pfizer, Roche, Bristol-Myers, Janssen, Speakers bureau: Abbvie, Pfizer, Roche, Bristol-Myers, Janssen DOI: 10.1136/annrheumdis-2019-eular.7480

\section{SAT0507 EVALUATION OF THE NEW CLASSIFICATION CRITERIA FOR PFAPA SYNDROME}

Fabio Crimi ${ }^{1}$, Manel Mejbri ${ }^{1}$, Véronique Hentgen ${ }^{2}$, Glory Dingulu ${ }^{2}$, Isabelle KonéPaut $^{3}$, Sophie Georgin-Lavialle ${ }^{4}$, Pascal Pillet ${ }^{5}$, Michael Hofer ${ }^{1}$, JIRcohorte. ${ }^{1}$ Pediatric Rheumatology, Lausanne, Switzerland; ${ }^{2}$ Pediatrics, Versailles, France; ${ }^{3}$ Pediatric rheumatology, Kremlin-Bicêtre, France; ${ }^{4}$ Immunology, Paris, France; ${ }^{5}$ Pediatric rheumatology, Bordeaux, France

Background: Modified Marshall criteria used for PFAPA syndrome have never been validated and are little used by the experts because the symptoms of monogenic fevers often overlap with PFAPA ones. A new set of classification criteria based on an international survey and a consensus conference in Genoa was developed in 2018.

Objectives: Evaluate the performance of the new criteria in a real-life setting

Methods: This is a multicentric, prospective and descriptive cohort study, through the recurrent fever module of the JIRcohorte platform. 417 patients diagnosed with PFAPA (187), monogenic fever syndromes (167) or unclassified recurrent fever syndrome $(U P F=63)$ from Swiss and French centers were enrolled in the study. The new classification criteria were applied to this cohort and we calculated their performance. We then analyzed which of the criteria performed the less well.

Results: One hundred fourteen from 187 (61\%) PFAPA patients met the new criteria, as well as 20/230 non-PFAPA patients (FMF: 3, MKD: 4 UPF: 13); 73 PFAPA patients did not meet the criteria. We calculated a specificity of $91.3 \%$ and a sensitivity of $60.9 \%$. The least satisfied criterion among PFAPA patients not meeting the criteria was "absence of skin rash". By removing this criterion, the sensitivity improved (81.2\%), but the specificity decreased slightly to $86 \%$.

Conclusion: Genoa 2017 classification criteria for PFAPA syndrome showed a good specificity but an insufficient sensitivity. Excluding the less satisfied criterion, the set reaches a sensitivity and specificity around $80 \%$ which could be a fair compromise for PFAPA classification criteria. Our study highlights the difficulty in establishing classification criteria due to the lack of gold standard for PFAPA diagnosis.

\section{REFERENCES}

[1] Vanoni F, Federici S, Antón J, Barron K, Brogan P, De Benedetti F, Dedeoglu F, Demirkaya E, Hentgen V, Kallinich T, Laxer R, Russo R, Toplak N, Uziel Y, Martini A, Ruperto N, Gattorno M, Hofer M. An international Delphi survey for the definition of the variables for the development of new classification criteria for Periodic Fever Aphthous stomatitis Pharyngitis Cervical Adenitis (PFAPA). Pediatr Rheumatol Online J. 2018, 16(1):27.

Disclosure of Interests: Fabio Crimi: None declared, Manel Mejbri: None declared, Véronique Hentgen Consultant for: SOBI, Novartis, Abbvie, Speakers bureau: Novartis, Glory Dingulu: None declared, Isabelle KonéPaut Grant/research support from: SOBI has supported drug product (anakinra) for the presented study, Consultant for: SOBI, Novartis, Pfizer, Abbvie, UCB, CHUGAI, ROCHE, Sophie Georgin-Lavialle Consultant for: novartis, sobi, Speakers bureau: novartis, sobi, Pascal Pillet: None declared, michael hofer Grant/research support from: novartis, SOBI, Consultant for: Novartis, SOBI

DOI: 10.1136/annrheumdis-2019-eular.8057

\section{SAT0508 AN INTERNATIONAL SURVEY ON APPROACHES TOWARDS IMMUNISATION IN CHILDREN WITH RHEUMATIC DISEASES: A REPORT OF THE PRES VACCINATIONS WORKING GROUP}

Elena Moraitis $^{1}$, D Maritsi ${ }^{2}$, Yosef Uziel $^{3}$, Gecilmara Salviato Pileggi $^{4}$ Raju Khubchandani ${ }^{5}$, Marc Jansen ${ }^{6}$, Nico Wulffraat ${ }^{6}$, Natasa Toplak ${ }^{7} .{ }^{1} \mathrm{GOSH}$ London, United Kingdom; ${ }^{2}$ NKUA, Athens, Greece; ${ }^{3}$ MMC, Kfar Saba, Israel; ${ }^{4}$ FACISB, Barreros, Brazil; ${ }^{5}$ SRCC, Mumbai, India; ${ }^{6}$ UMC, Utrecht, Netherlands; ${ }^{7}$ UMC, Ljubljana, Slovenia

Background: Data on immunisation practices in Paediatric Rheumatology are scarce. EULAR recommendations for vaccination in paediatric patients with rheumatic disease (RD) were published in 2011. In some countries national recommendations for vaccination of immunocompromised patients are available.

Objectives: To ascertain the opinion and current practices of paediatric rheumatologists with regards to immunisation of children with rheumatic diseases (RD), and to establish their confidence to immunise the patients with $\mathrm{RD}$ on immunosuppressive medication with live vaccines in light of the evidence available.

Methods: An online survey of practices and opinions towards immunisa tions with a focus on immunisation of the immunocompromised child with $\mathrm{RD}$ was distributed to paediatric rheumatologists across the globe. Responses were collected via SurveyMonkey and descriptive analysis was performed. Responses were anonymous with the exception of identification of the country and length of practice.

Results: 289 responses were received from 53 countries in Europe, North and South America, Australia and Asia. 35\% of the respondents had over 15 years of practice in Paediatric Rheumatology, while $42 \%$ had 5 . 15 years.

$57 \%$ responded that all immunisations or at least part of them are given in their paediatric rheumatology unit, and $60 \%$ that the vaccinations are mandatory in their country. 93\% of respondents support the immunisation of paediatric patients with $\mathrm{RD}, 6.9 \%$ responded that they are either not supportive/not sure/support only vaccinations with inactivated vaccines. $53 \%$ reported that national recommendations for immunisations of immu nosuppresed child are available but not specific to Paediatric Rheumatology. $41 \%$ of respondents inform their practice on immunisation of patients with RD based exclusively on the EULAR recommendations, $37.5 \%$ based on national guidelines, $8.5 \%$ on local guidelines and $10 \%$ on combinations of the above. $48 \%$ of clinicians would postpone vaccinations in all cases if disease is active.

In terms of immunisations with live vaccines of patients with JIA on immunosuppresive treatment, $41 \%$ of respondents would recommend the first dose of MMR or Varicella vaccines to patients with stable disease on Prednisolone $<1 \mathrm{mg} / \mathrm{kg} /$ day (maximum $20 \mathrm{mg}$ ) for less than 1 month or higher dose up to $2 \mathrm{mg} / \mathrm{kg} /$ day for less than 14 days, $14 \%$ would also recommend these vaccines if the above steroid dose was given in combination with Methotrexate (MTX) < 15mg/kg/week, 30\% would recom mend these vaccines if the patient was on MTX monotherapy. Comparable percentages reported confidence to also recommend booster doses of the two vaccines for the above drug combinations $(45 \%, 15.7 \%, 37 \%$, respectively), whilst up $10 \%$ of respondents would recommend them to patients on anti-TNF agent alone, and up to $7 \%$ for other biologics. For patients with SLE and quiescent disease on similar medications as above, $41 \%, 15 \%, 31 \%$, respectively, of clinicians reported confidence to recommend MMR or Varicella booster doses.

$48 \%$ of the respondents identified the reluctance of other health profes sionals involved in the process of immunisations as the main reason hampering the vaccination of paediatric patients with RD, whilst $22 \%$ indicated parental refusal or hesitancy.

Conclusion: There is variation in practice and opinions worldwide with regards to immunisations in paediatric patients with $\mathrm{RD}$, and this likely reflects the discrepancies between national guidelines for immunisation of immunosuppressed child and also national policies. More studies are required, but there is an increasing vote of confidence towards immunisation of patients on lower grade immunosuppression with MMR or varicella vaccines

Disclosure of Interests: None declared

DOI: 10.1136/annrheumdis-2019-eular.8063 